\title{
PLANEJAMENTO TRIBUTÁRIO EM UMA INDÚSTRIA DE CONFECÇÕES
}

\author{
TAX PLANNING IN A CLOTHING INDUSTRY
}

Andrey Araujo ${ }^{1}$

https://orcid.org/0000-0002-6878-1558

Diones Kleinibing Bugalho ${ }^{2}$

https://orcid.org/0000-0002-4636-5086

Francieli Morlin Bugalho 3

https://orcid.org/0000-0002-7302-5319

Januario José Monteiro ${ }^{4}$

https://orcid.org/0000-0002-7000-4256

Recebido em: 23 mar. 2020

Aceito em: 10 dez. 2021

Como citar este artigo: ARAUJO, A.; BUGALHO, D. K.; BUGALHO, F. M.; MONTEIRO, J. J. PLANEJAMENTO TRIBUTÁRIO EM UMA INDÚSTRIA DE CONFECÇÕES. Revista Visão: Gestão

Organizacional, Caçador (SC), Brasil, v. 10, n. 2, p. 77-92, 2021. DOI:

10.33362/visao.v10i2.2204. Disponível em:

https://periodicos.uniarp.edu.br/index.php/visao/article/view/2204.

Resumo: A presente pesquisa teve por objetivo identificar o regime tributário que fosse menos oneroso à uma indústria de confecções, ou seja, ocasionando a menor carga tributária. Com a finalidade de realizar o planejamento tributário, foram efetuadas diversas consultas em pesquisas existentes e nas legislações aplicáveis, para que tudo fosse praticado por meios legais, sendo caracterizada pela elisão fiscal, trata-se de uma pesquisa qualitativa, onde os dados da pesquisa foram coletados através do sistema eletrônico de processamento de dados, relatórios, balanços e demonstrações contábeis. O período analisado refere-se ao ano de 2018, pelo qual foram efetuados os cálculos pelo regime tributário Lucro Real o pela contabilidade responsável pela empresa. Foram comparados os valores dos tributos de PIS, COFINS, IRPJ, CSLL, ICMS, IPI e CPP, onde ocorreu os comparativos entre os regimes de tributação Lucro Real e Lucro Presumido, com a finalidade de demonstrar o melhor regime aplicável. Os resultados indicam que o melhor regime tributário para o período analisado foi o Lucro Real, identificando que está enquadrada na melhor forma de apuração.

Palavras-Chave: Lucro Real. Lucro Presumido. Regime Tributário. Tributos.

\footnotetext{
${ }^{1}$ Bacharel em Ciências Contábeis pela Faculdade Mater Dei - Pato Branco - PR. E-mail: andrey_sci@hotmail.com.

${ }^{2}$ Mestrando em Ciências Contábeis e Administração - PPGCCA. Universidade Comunitária da Região de Chapecó - UNOCHAPECÓ. E-mail: diones.bugalho@unochapeco.edu.br.

3 Mestranda em Contabilidade - PPGC. Universidade Federal de Santa Catarina - UFSC. E-mail: fran_morlin@hotmail.com.

${ }^{4}$ Doutorando em Contabilidade - UFSC. E-mail: januariomonteiromonteiro@gmail.com.
} 
Abstract: The present research aimed to identify the tax regime that would be less costly to a clothing industry, that is, causing the lowest tax burden. In order to carry out tax planning, several consultations were carried out in existing research and in the applicable legislation, so that everything could be practiced by legal means, being characterized by tax avoidance, it is a qualitative research, where the research data were collected through the electronic data processing system, reports, balance sheets and financial statements. The period analyzed refers to the year 2018, where calculations have already been made under the taxable profit regime by the accounting responsible for the company. The values of the PIS, COFINS, IRPJ, CSLL, ICMS, IPI and CPP taxes were compared, where the comparisons between the taxable income tax system and the presumed income tax occurred, in order to demonstrate the best applicable regime. The results indicate that the best tax regime for the period analyzed is the Real Profit, identifying that it is framed in the best form of calculation.

Keywords: Real Profit. Presumed profit. Tax regime. Taxes.

\section{INTRODUÇÃO}

A ciência contábil, por vezes é discutida sobre sua importância no cenário empresarial nos vários ramos em que atua. Pois, é através dela que se retira o maior número de informações para tomada de decisões, gestão e controle do patrimônio, além de permitir o planejamento de toda e qualquer entidade. Nesse sentido o autor Marion (2003, p. 136) enfatiza que "[...] a contabilidade pode ser considerada como sistema de informação destinada a prover seus usuários de dados para ajudá-los na tomada de decisões".

Percebe-se que seu objetivo é identificar a dimensão nos negócios empresariais, conhecer as relações jurídicas, econômicas e sociais. Ao analisar os meios empresariais, verifica-se que uma das maiores preocupações dos empresários na atualidade, se sustenta em encontrar meios para evitar a alta carga tributária.

Desta forma, para que uma empresa possa ter um bom desempenho, independente do seu porte ou área de operação, é essencial o uso da contabilidade não somente como meio de controle de ativos, passivos, receitas, custos e despesas, mas principalmente, na busca de alcançar um excelente planejamento tributário, através de alternativas viáveis da diminuição legal dos encargos tributários, a fim de obter, na medida do possível, a menor carga tributária, oportunizando para empresa o melhor aproveitamento dos seus recursos econômicos (FABRETTI, 2009).

Para Latorraca (2000) costuma-se denominar o planejamento tributário como a atividade empresarial que, desenvolvendo-se de forma estritamente preventiva, projeta os atos e fatos administrativos com o objetivo de informar quais os ônus tributários em cada uma das opções legais disponíveis.

Do mesmo modo, Alves (2006 p.2) afirma que o planejamento é a atividade que, feita 
de maneira exclusivamente preventiva, prevê, coordena e projeta atos e negócios com o objetivo de determinar qual é o meio menos oneroso para a realização destes mesmos atos e negócios. Oliveira (2013) salienta que atualmente o contador deve estar atento e obedecer às normas de contabilidade e também as normas de legislação tributária, para a correta apuração da situação econômica da empresa.

Com base nestes itens foi elaborado o problema de pesquisa: Qual regime tributário apresenta a menor carga tributária para uma indústria de confecções? Para responder o problema, traçou-se o objetivo de identificar o regime tributário que fosse menos oneroso à uma indústria de confeç̧ões.

O estudo justifica-se devido sua complexidade, no quadro federal atual, pode-se apresentar os próximos tributos decorrendo como os mais complicados para apuração: Programa de Integração Social - PIS, Contribuição para Financiamento da Seguridade Social COFINS, Contribuição Social Sobre o Lucro Líquido - CSLL, Imposto de Renda Pessoa Jurídica IRPJ (MUNIZ, 2012).

Enquanto na esfera estadual, o Imposto sobre Circulação de Mercadorias e Serviços ICMS se sobressai pela dificuldade no momento da apuração. São 27 legislações diferentes, o que provoca um problema muito discutido e conhecido como a "Guerra Fiscal", que outorga os benefícios fiscais, com o propósito de atrair investimentos ao Estado (OLIVEIRA et al. 2012).

A autoridade que o fisco possui na esfera Federal, Estadual e municipal para com o contribuinte, requer amplo conhecimento do responsável pela área tributária. Este especialista deve compreender os tributos que podem atingir uma entidade econômica, bem como, entender e saber como julgar o melhor regime de tributação no qual ela pode se enquadrar (CREPALDI, 2012). O planejamento tributário, carece de suporte da legislação, para que assim funcione de modo eficaz e eficiente. Eficaz quando se diz a respeito de meios legais para a utilização desta ferramenta e eficiente em relação a redução de pagamento de impostos (FABRETTI, 2009).

\section{REVISÃO DA LITERATURA}

A revisão da literatura da presente pesquisa consiste em discutir os regimes tributários do Lucro Presumido e Lucro Real e como estes afetam o planejamento tributário.

\section{LUCRO PRESUMIDO}

Conforme o Art. 13 da Lei $n^{\circ}$ 9.718/98, empresas que possuam no ano calendário anterior um registro com a receita bruta menor ou igual a $\mathrm{R} \$ 78$ milhões, podem utilizar imediatamente, o lucro presumido como alternativa de regime tributário para a pessoa jurídica, conforme enunciado: 
Art. 13. A pessoa jurídica cuja receita bruta total no ano-calendário anterior tenha sido igual ou inferior a $\mathrm{R} \$ 78.000 .000,00$ (setenta e oito milhões de reais) ou a $\mathrm{R} \$$ $6.500 .000,00$ (seis milhões e quinhentos mil reais) multiplicado pelo número de meses de atividade do ano-calendário anterior, quando inferior a 12 (doze) meses, poderá optar pelo regime de tributação com base no lucro presumido (Redação dada pela lei $n^{\circ} 12.814$, de 2013).

O lucro presumido difere da definição do lucro real, ciente de que se trata pretensão por parte do fisco, daquilo que seria o ganho das empresas caso a contabilidade não existisse. Deste modo, o lucro presumido pretendeu simplificar a apuração da base de cálculo para umas empresas e também para apuração e recolhimento de imposto de renda e contribuição social (OLIVEIRA, 2004).

Para apuração da CSLL, no lucro presumido, encontra-se neste regime a base de cálculo que se aplica uma porcentagem de 12\% para operações com mercadorias e 32\% para operações sobre serviços. Também soma-se a este valor as receitas com ganho de capital, aplicações financeiras com intuito de rendimentos e demais resultados positivos de receitas não alcançadas pela incidência dos percentuais. Sendo assim, após todo processo para a base de cálculo do tributo, é determinada a aplicação de $9 \%$ para obter o valor devido do tributo (CASSONE, 2010).

Dando-se ênfase conforme já exposto, Fabretti (2013) afirma que a base de cálculo da Contribuição Social sobre o Lucro Líquido é a mesma utilizada para o cálculo do Imposto de Renda para Pessoa Jurídica. O levantamento ou apuração dos tributos através deste regime, segundo Oliveira (2010), é exercida trimestralmente, sendo nos dias, 31 de março, 30 de junho, 30 de setembro e 31 de dezembro de cada ano-calendário.

Em relação ao PIS e COFINS, são duas contribuições federais com finalidades diferentes, onde uma e outra incidem sobre o faturamento e de fato são idênticas, de acordo com as normas e leis de ambos os tributos, alterando apenas a alíquota. No caso no Lucro Presumido, as alíquotas aplicadas sobre o faturamento são de 0,65\% e 3,00\%, sendo uma das características a cumulatividade, isto é, inexiste créditos na operação de compra (FABRETTI, 2013).

\section{LUCRO REAL}

Neste regime, Chaves (2010) explica que o cálculo do imposto é efetuado segundo registros contábeis elaborados em concordância com as leis fiscais e comerciais, portanto, é indispensável a conservação da escrita contábil, principalmente do Livro de Apuração do Lucro Real - LALUR. O autor acrescenta ainda que o lucro real é o resultado contábil (receita menos os custos e despesas), ajustados pelas adições e exclusões. Esses ajustes devem ser demonstrados no Livro de Apuração do Lucro Real - LALUR.

Portanto o lucro real, é a base de cálculo do imposto de renda através do desfecho 
demonstrado na contabilidade, é o formato de tributação mais completo para efetuar o cálculo do Imposto de Renda e a Contribuição Social sobre o lucro, onde a base de cálculo surge mediante o lucro contábil com as devidas adições, exclusões e compensações do Livro de Apuração do Lucro Real - LALUR (YOUNG, 2009).

Para Fabretti (2009) quando analisado somente o Imposto de Renda da Pessoa Jurídica (IRPJ) e a Contribuição Social sobre o Lucro Líquido (CSLL), na maioria dos casos é a melhor opção, porque a empresa somente paga os referidos tributos quando obtém lucro. Entretanto, Oliveira (2013) afirma que no planejamento tributário deve ser levado em conta todos os tributos incidentes sobre a atividade da organização para encontrar o regime tributário de menor onerosidade.

Quanto à base de cálculo para a apuração da CSLL, Fabretti (2013, p. 255) expõe em seu trabalho da seguinte forma: "Aplicam-se à Contribuição Social sobre o Lucro, nas mesmas normas de apuração e de pagamento estabelecidas para o imposto de renda das pessoas jurídicas $[. . .]^{\prime \prime}$, ou seja, que primeiramente a base deste tributo era igual à do IRPJ, conforme explica o Art.57 da Lei nº 8.981 de janeiro de 1995: Art. 57.

\footnotetext{
Aplicam-se à Contribuição Social sobre o Lucro (Lei $n^{\circ} 7.689$, de 1988) as mesmas normas de apuração e de pagamento estabelecidas para o imposto de renda das pessoas jurídicas, inclusive no que se refere ao disposto no art. 38, mantidas a base de cálculo e as alíquotas previstas na legislação em vigor, com as alterações introduzidas por esta Lei (Redação dada pela Lei nº 9.065, de 1995).
}

A partir disso, Oliveira (2013) menciona que a base de cálculo da CSLL é estipulada pela decorrência dos resultados do trimestre, antes da provisão para sua quitação, assim como do IRPJ, sendo assentadas pelas adições, exclusões e compensações, tal como é o caso dos resultados pregressos negativos, denominados negativos, onde é limitada a $30 \%$ do lucro obtido no exercício.

Em relação ao PIS e COFINS do Lucro Real, a concessão de formação de créditos não ocorre em todas as operações de entrada, pois, é preciso diagnosticar a atividade da entidade, tais como o tipo de operação de entrada, sendo assim, o crédito é averiguado toda via pela visão individual do contribuinte que adquire produtos e serviços e não se permite geração de créditos em obtenções de mercadorias e serviços por pessoa física. O Lucro Real é conhecido ainda pelo princípio da Não-cumulatividade dos tributos, ou seja, permite-se a geração de créditos, e usa-se alíquotas de 1,65\% e 7,6\% para PIS e COFINS respectivamente (FABRETTI, 2013).

Em relação aos regimes tributários, Oliveira et al. (2012) assegura que o Imposto de Circulação de Mercadorias e Serviços - ICMS, Produtos Industrializados - IPI não possuem diferenças entre os regimes tributários do lucro presumido e lucro real, do mesmo modo que a Contribuição Previdenciária Patronal - CPP, estes três tributos possuem apenas diferenças no regime do Simples Nacional. 


\section{PLANEJAMENTO TRIBUTÁRIO VERSUS SONEGAÇÃO}

Segundo Fabretti (2007), para que seja lícito o planejamento tributário, o mesmo não poderá ter qualquer conexão com adulterações ou fraudes, ocorrendo que a legislação autoriza os contribuintes a escolher acontecimentos autorizados ou não proibidas pela lei, mesmo que este hábito prejudique o Estado e nem por esse motivo, caracteriza-se sonegação fiscal.

Oliveira (2006) afirma que a sonegação é toda ação ou omissão dolosa tendente a impedir ou retardar, total ou parcialmente, o conhecimento por parte da autoridade fazendária, resumindo a explanação do autor, significa que toda e qualquer forma fraudulenta de impossibilitar, por parte ou total, a ocorrência do fato gerador se constitui sonegação.

O Planejamento tributário não pode ser confundido com a sonegação, uma vez que planejar é decidir entre duas ou mais escolhas lícitas, na qual dentre elas seja capa de apresentar os melhores resultados para a empresa, no entanto sonegar, é lidar com meios ilegais para deixar de recolher tributos que são devidos, sendo assim, tende a impedir ou atrasar a ciência do fato gerador da obrigação fiscal (BORGES, 2002).

Para Oliveira (2009) é primordial diferenciar elisão fiscal de evasão fiscal para que se possa compreender o planejamento tributário e também definir que a principal diferença está no fato da licitude das condutas onde o contribuinte busca a economia no recolhimento dos rendimentos que serão remetidos ao Estado.

O planejamento tributário antes da ocorrência do fato gerador do tributo provoca a elisão fiscal, isto é, a diminuição da carga tributária através de meios legais. Por essa razão é visto como planejamento preventivo, é uma maneira de encontrar economias legais no recolhimento dos tributos da entidade, sendo assim, visado como o método que segue a legislação, ou seja, de maneira lícita (FABRETTI, 2009).

Malkowski (2000, p. 42), diferencia evasão e elisão como uma fronteira do lícito e do ilícito dizendo que "o grande problema se coloca quando se cuida de estabelecer os limites que separam o território da chamada economia licita dos tributos e o campo da evasão, temos de reconhecer que essa fronteira existe."

A elisão fiscal é exercida pelos administradores da empresa antes do evento do fato gerador da obrigação tributária, sendo assim, não ocorrendo a incidência tributária e também não existindo a necessidade da quitação do produto (COELHO, 1998).

Evasão fiscal é totalmente o oposto de elisão fiscal, são condutas cometidas fora da lei e relativas a fatos geradores da obrigação tributária já ocorrida, um exemplo é quando uma pessoa física prestando um serviço para outra, onde firmam um documento de doação para não quitar o imposto de renda, ou seja, o imposto é devido, porém, foi escondido por uma ocultação na documentação (HIGUCHI, 2015). 


\section{METODOLOGIA}

A presente pesquisa é classificada metodologicamente como descritiva com abordagem qualitativa, a qual foi aplicada a uma indústria de confecções. Para coleta dos dados, utilizou-se dos relatórios contábeis existentes na empresa, como os livros de entrada e saída, balanço patrimonial e demonstração do resultado do exercício, além das apurações realizadas pelo escritório contábil sob o regime tributário do Lucro Real, regime pelo qual a empresa estava enquadrada.

Deste modo, a pesquisa elaborada, embasa-se no método descritivo, pelo qual o pesquisador observa, registra, analisa e ordena dados, sem manipulá-los, isto é, sem interferência do pesquisador. Procura descobrir a frequência com que um fato ocorre, sua natureza, suas características, causas, relações com outros fatos. Assim, para coletar tais dados, utiliza-se de técnicas especificas (PRODANOV E FREITAS, 2013).

Referente a abordagem, foi realizado uma análise de como se encontrava uma empresa real, sucessivamente, efetuou-se uma pesquisa bibliográfica constituída através de livros, revistas bem como a legislação a respeito do tema analisado, sendo assim, usou-se o método qualitativo para este estudo.

Prodanov e Freitas (2013), comentam também sobre a abordagem qualitativa, onde similarmente se enquadra este trabalho, pois, foi realizado uma pesquisa descritiva sobre assunto baseando-se em autores da área de tributos e afins. Ainda em concordância com o conhecimento dos autores, a análise qualitativa busca uma ligação entre o mundo real e o sujeito que não se traduz somente através de números, onde é colocado em evidência a interpretação e os significados da pesquisa, sendo assim, buscou-se por meio de situações vividas pela empresa, criar um planejamento tributário a ser utilizado também futuramente, por meio de dados atuais.

\section{RESULTADOS E DISCUSSÃO}

Conforme discutido anteriormente a empresa em questão, estava enquadrada no Real no ano de 2018, inicialmente se faz necessário apresentar os valores da apuração dos tributos sobre o lucro nesta metodologia de apuração com base na Demonstração do Resultado do Exercício da empresa. Para tanto, foi elaborada a Tabela 1:

Tabela 1 - DRE Anual Sintética - Lucro Real

\begin{tabular}{l|lc}
\hline APURAÇÃO DO LUCRO REAL - ANUAL & \multicolumn{2}{l}{} \\
\hline RECEITA OPERACIONAL BRUTA & R\$ & $5.005 .838,16$ \\
\hline (-) Cancelamentos e Devoluções & R\$ & $248.120,34$ \\
\hline DEDUÇÕES DA RECEITA BRUTA & R\$ & $209.825,00$ \\
\hline (-) ICMS & R\$ & $95.920,00$ \\
\hline
\end{tabular}




\begin{tabular}{|c|c|c|}
\hline$(-)|P|$ & RS & $39.966,67$ \\
\hline$(-)$ PIS & $R \$$ & $13.189,00$ \\
\hline (-) COFINS & RS & $60.749,33$ \\
\hline RECEITA OPERACIONAL LÍQUIDA & $\mathrm{R} \$$ & $4.696 .968,49$ \\
\hline$(-) \mathrm{CMV}$ & R\$ & $2.883 .691,20$ \\
\hline LUCRO BRUTO & $\mathrm{R} \$$ & $1.813 .277,29$ \\
\hline (-) DESPESAS OPERACIONAIS & $\mathrm{R} \$$ & $1.406 .001,63$ \\
\hline (-) Despesas Administrativas & $R \$$ & $350.761,90$ \\
\hline (-) Despesas de Pessoal & RS & $941.248,08$ \\
\hline (-) Despesas Gerais & RS & $89.413,01$ \\
\hline (-) Despesas Financeiras & RS & $24.578,64$ \\
\hline RESULTADO ANTES DO IRPJ E CSLL & $\mathrm{R} \$$ & $407.275,66$ \\
\hline IRPJ (15\%) & RS & $61.091,35$ \\
\hline IRPJ Adicional (10\%) & RS & $16.727,57$ \\
\hline CSLL (9\%) & RS & $36.654,81$ \\
\hline LUCRO/PREJUÍZO DO EXERCÍCIO & R\$ & $292.801,94$ \\
\hline
\end{tabular}

Fonte: Dados da pesquisa

Os dados da Demonstração do Resultado do Exercício - DRE da Tabela 1, permitem visualizar que no ano de 2018, a empresa em análise teve seu resultado antes do IRPJ e CSLL no valor de $\mathrm{R} \$ 407.275,66$, sendo assim, deduzido do resultado $15 \%$ de IRPJ, 10\% de IRPJ adicional e $9 \%$ de CSLL, obtendo-se assim um lucro do exercício no valor de $\mathrm{R} \$ 292.801,94$.

Vale ressaltar que a porcentagem de $10 \%$ de IRPJ adicional, se dá ao fato de que a parcela excedeu ao valor resultante da multiplicação de $\mathrm{R} \$ 20.000,00$ correspondentes ao número de meses respectivos ao período de apuração. Ao ser efetuada a apuração do IRPJ e da CSLL pelo regime tributário Lucro Real, é preciso efetuar também os ajustes do lucro, estes ajustes interferem diretamente na base de cálculo do Lucro/Prejuízo da empresa, sendo aplicada as alíquotas de 15\% de IRPJ, 9\% de CSLL e ainda 10\% de adicional de IRPJ.

É possível observar também que a empresa teve um faturamento total no ano de mais de 5 milhões, e em função disso, não pode ser enquadrada no regime tributário do Simples Nacional, que atualmente possui um limite de 4,8 milhões. Ou seja, resta apenas os regimes do Lucro Real e do Lucro Presumido.

\section{APURAÇÃO LUCRO PRESUMIDO}

Na apuração de PIS e COFINS utilizou-se as alíquotas básicas nas receitas tributáveis, que no Lucro Real, as alíquotas são de 1,65\% e 7,6\% para PIS e COFINS respectivamente, portanto estes tributos seguem o princípio da Não Cumulatividade, ou seja, os valores de entrada podem ser fatores de crédito, e assim abater do valor apura do em relação as operações de saída.

No caso do Lucro Presumido, tem-se o oposto do Lucro Real, a apuração dos tributos 
seguem o princípio da Cumulatividade, onde é impedido a geração de créditos dos valores de entrada, porém, existe o benefício de recolher tributos sob alíquotas menores nos documentos de saída que são tributadas, as alíquotas básicas a serem aplicadas são de 0,65\% para PIS e 3\% para COFINS.

As tabelas que serão exibidas posteriormente, foram desenvolvidas com base no faturamento atual da empresa excluindo-se as operações sem incidência das contribuições, no caso o mesmo calculado no Lucro Real, porém os valores de contribuição de PIS e COFINS serão apurados com base no Lucro Presumido.

Tabela 2 - Apuração de PIS e COFINS Cumulativo - $1^{\circ}$ Trimestre

\begin{tabular}{|c|c|c|c|c|}
\hline 1ㅇ Trimestre & Janeiro & Fevereiro & Março & Total 10 Trimestre \\
\hline Base de Créditos & $R \$ 145.501,25$ & $R \$ 122.950,78$ & $R \$ 168.614,22$ & $R \$ 437.066,25$ \\
\hline Crédito de PIS & $\mathrm{RS}$ & $\mathrm{RS}$ & $\mathrm{RS}$ & $R \$$ \\
\hline Crédito de COFINS & $R \$$ & $R \$$ & $R \$$ & $R \$$ \\
\hline Base de Débitos & $R \$ 207.103,11$ & $R \$ 198.764,89$ & $R \$ 214.678,27$ & $R \$ 620.546,27$ \\
\hline Débitos de PIS & $\mathrm{R} \$ 1.346,17$ & $\mathrm{R} \$ 1.291,97$ & $\mathrm{R} \$ 1.395,41$ & $R \$ 4.033,55$ \\
\hline Débitos de COFINS & $R \$ 6.213,09$ & $R \$ 5.962,95$ & $R \$ 6.440,35$ & $\mathrm{R} \$ 18.616,39$ \\
\hline
\end{tabular}

Fonte: Dados da pesquisa

A Tabela 2, apresenta os valores a pagar de PIS e COFINS pelo Regime Cumulativo calculados no $1^{\circ}$ Trimestre de 2018, correspondente aos meses de Janeiro, Fevereiro e Março, observa-se que o valor a pagar de PIS é de $\mathrm{R} \$ 4.033,55$ e para COFINS é de $\mathrm{R} \$ 18.616,39$.

Conforme mencionado anteriormente, as alíquotas empregadas as receitas de venda e foram alíquotas básicas de 0,65\% e 3\% para PIS e COFINS nesta ordem. Ressalta-se ainda, que inexiste créditos de PIS e COFINS, justificando a existência dos campos zerados, para fins de comparação com o Lucro Real através da não cumulatividade.

Tabela 3 - Apuração de PIS e COFINS Cumulativo - $2^{\circ}$ Trimestre

\begin{tabular}{l|l|l|l|l}
\hline 2o Trimestre & Abril & Maio & Junho & Total 2o Trimestre \\
\hline Base de Créditos & $\mathrm{R} \$ 152.647,59$ & $\mathrm{R} \$ 155.791,35$ & $\mathrm{R} \$ 219.156,24$ & $\mathrm{R} \$ 527.595,18$ \\
\hline Crédito de PIS & $\mathrm{R} \$-$ & $\mathrm{R} \$-$ & $\mathrm{R} \$$ & $\mathrm{R} \$$ \\
\hline Crédito de COFINS & $\mathrm{R} \$$ & $\mathrm{R} \$$ & $\mathrm{R} \$$ & - \\
\hline Base de Débitos & $\mathrm{R} \$ 199.367,12$ & $\mathrm{R} \$ 212.456,28$ & $\mathrm{R} \$ 272.410,60$ & $\mathrm{R} \$ 684.234,00$ \\
\hline Débitos de PIS & $\mathrm{R} \$ 1.295,89$ & $\mathrm{R} \$ 1.380,97$ & $\mathrm{R} \$ 1.770,67$ & $\mathrm{R} \$ 4.447,52$ \\
\hline Débitos de COFINS & $\mathrm{R} \$ 5.981,01$ & $\mathrm{R} \$ 6.373,69$ & $\mathrm{R} \$ 8.172,32$ & $\mathrm{R} \$ 20.527,02$ \\
\hline
\end{tabular}

Fonte: Dados da Pesquisa

Os valores totais apurados no $2^{\circ}$ trimestre de 2018 com base no Lucro Presumido, foram no montante de $\mathrm{R} \$ 4.447,52$ e $\mathrm{R} \$ 20.527 .02$ para PIS e COFINS respectivamente, demonstrando através da análise que as operações de saída através do faturamento da empresa, foram mais elevadas quando comparadas com o primeiro trimestre, com base no Lucro Presumido.

No caso do Lucro Presumido, como inexiste créditos das operações de entrada, quanto 
maior forem as receitas tributadas no período, maior será o valor a recolher de PIS e COFINS, conforme é demonstrado na Tabela 3 acima, onde os valores foram crescentes mês a mês em virtude do aumento de recitas tributadas.

A Tabela 4 demonstra a apuração referente ao terceiro trimestre de 2018.

Tabela 4 - Apuração de PIS e COFINS Cumulativo - $3^{\circ}$ Trimestre

\begin{tabular}{|c|c|c|c|c|}
\hline 30 Trimestre & Julho & Agosto & Setembro & Total 3ㅇ Trimestre \\
\hline Base de Créditos & $\mathrm{R} \$ 162.447,10$ & $R \$ 136.761,18$ & $R \$ 140.869,33$ & $\mathrm{R} \$ 440.077,61$ \\
\hline Crédito de PIS & $R \$$ & $R \$$ & $R \$$ & $R \$$ \\
\hline Crédito de COFINS & $\mathrm{RS}$ & $\mathrm{RS}$ & $R \$$ & $\mathrm{RS}$ \\
\hline Base de Débitos & $\mathrm{R} \$ 199.713,12$ & $R \$ 190.555,81$ & $\mathrm{R} \$ 234.719,15$ & $R \$ 624.988,08$ \\
\hline Débitos de PIS & $\mathrm{R} \$ 1.298,14$ & $\mathrm{R} \$ 1.238,61$ & $\mathrm{R} \$ \quad 1.525,67$ & $\mathrm{R} \$ 4.062,42$ \\
\hline Débitos de COFINS & $R \$ 5.991,39$ & $R \$ 5.716,67$ & $R \$ 7.041,57$ & $R \$ 18.749,64$ \\
\hline
\end{tabular}

Fonte: Dados da pesquisa

Sendo calculada de maneira igual ao do $2^{\circ}$ trimestre e baseada no regime do Lucro Presumido, através faturamento das vendas, os resultados obtidos para o 3 trimestre de 2018 foram respectivamente de $\mathrm{R} \$ 4.062,42$ de PIS e de COFINS R\$18.749,64 para o trimestre, sendo o mês com o maior valor de recolhimento o mês de setembro, pelo fato da base de cálculo dos débitos ser maior, totalizando $\mathrm{R} \$ 234.719,15$.

Tabela 5 - Apuração de PIS e COFINS Cumulativo - $4^{\circ}$ Trimestre

\begin{tabular}{|c|c|c|c|c|}
\hline 4음 Trimestre & Outubro & Novembro & Dezembro & Total 40 Trimestre \\
\hline Base de Créditos & $\mathrm{R} \$ 187.410,57$ & $\mathrm{R} \$ 196.784,17$ & $\mathrm{R} \$ 124.388,75$ & $R \$ 508.583,49$ \\
\hline Crédito de PIS & $\mathrm{RS}$ & $\mathrm{RS}$ & $R \$$ & $R \$$ \\
\hline Crédito de COFINS & $\mathrm{R} \$$ & $\mathrm{R} \$$ & $\mathrm{RS}$ & $\mathrm{RS}$ \\
\hline Base de Débitos & $\mathrm{R} \$ 236.995,10$ & $\mathrm{R} \$ 255.410,38$ & $R \$ 290.482,02$ & $\mathrm{R} \$ 782.887,50$ \\
\hline Débitos de PIS & $\mathrm{R} \$ 1.540,47$ & $R \$ 1.660,17$ & $\mathrm{R} \$ 1.888,13$ & $R \$ 5.088,77$ \\
\hline Débitos de COFINS & $R \$ 7.109,85$ & $R \$ 7.662,31$ & $R \$ 8.714,46$ & $R \$ 23.486,63$ \\
\hline
\end{tabular}

Fonte: Dados da pesquisa

Para o último trimestre de 2018 nos meses de Outubro, Novembro e Dezembro, podese concluir após a análise da Tabela 5, que houve um aumento considerável de débito de PIS e COFINS, comparado ao $3^{\circ}$ trimestre, onde nos meses de Novembro e Dezembro obteve o maior valor entre os 10 outros meses no ano civil de 2018. Calculou-se um valor de $\mathrm{R} \$ 5.088,77$ para PIS e R\$23.486,63 para COFINS no $4^{\circ}$ trimestre de 2018.

O aumento significativo das contribuições, ocorreu pelo motivo da base de cálculo dos débitos ser crescente nos três últimos meses do ano, conforme é possível observar na Tabela 5 acima representada.

Para a apuração do IRPJ e CSLL com base no Regime Tributário do Lucro Presumido que é considerado um sistema simples de apuração, normalmente a empresa que opta por este regime possui uma margem de lucro elevada, pelo fato de que se presume um certo lucro para a empresa conforme sua atividade, por isso o nome Lucro Presumido. 
O cálculo para apuração destas contribuições pelo Lucro Presumido foi desenvolvido com base no faturamento da DRE da empresa no qual está sendo utilizada como objeto de estudo, onde anteriormente foi demonstrada na Tabela 1. Para que seja possível chegar ao lucro operacional bruto que será demonstrado nas próximas tabelas, em que foram aplicadas as alíquotas de presunção de $8 \%$ para IRPJ e $12 \%$ para CSLL para se chegar ao lucro presumido, e posteriormente multiplicar pelas alíquotas do imposto propriamente dito, cujas alíquotas são $15 \%$ e $9 \%$ para IRPJ e CSLL respectivamente.

Os próximos dados apresentados, demonstram o montante dos valores de apuração do IRPJ e CSLL de modo trimestral, sendo a única forma de apuração viável onde a legislação determina que seja o utilizado o Lucro Presumido, diferentemente do Lucro Real, onde a empresa pode escolher em apurar seus impostos de forma trimestral ou anual.

Tabela 6 - Apuração do IRPJ e CSLL - Lucro Presumido - $1^{\circ}$ Trimestre

\begin{tabular}{l|l|l}
\hline ESPECIFICAÇÃO IRPJ CSLL & IRPJ & CSLL \\
\hline Receita Operacional Bruta - Venda de Mercadorias & $\mathrm{R} \$ 1.118 .356,79$ & $\mathrm{R} \$ 1.118 .356,79$ \\
\hline Percentual do Lucro Fixado Fiscalmente (Presunção Lucro) & $8 \%$ & $12 \%$ \\
\hline Lucro Presumido Venda de Mercadorias & $\mathrm{R} \$ 89.468,54$ & $\mathrm{R} \$ 134.202,82$ \\
\hline Receita Financeira Tributada Integralmente & $\mathrm{R} \$ 12.957,15$ & $\mathrm{R} \$ 12.957,15$ \\
\hline Lucro Presumido Total & $\mathrm{R} \$ 102.425,69$ & $\mathrm{R} \$ 147.159,97$ \\
\hline Alíquotas de IRPJ e CSLL & $15 \%$ & $9 \%$ \\
\hline Valor de IRPJ e CSLL - Antes do Adicional & $\mathrm{R} \$ 15.363,85$ & $\mathrm{R} \$ 13.244,40$ \\
\hline Adicional de IRPJ - 10\% Sobre o que ultrapassar 60 mil & $\mathrm{R} \$ 4.242,57$ & $\mathrm{R} \$$ \\
\hline Valor a pagar de IRPJ e CSLL & $\mathrm{R} \$ 19.606,42$ & $\mathrm{R} \$ 13.244,40$ \\
\hline Fonte: Dados da PeSquisa
\end{tabular}

Fonte: Dados da pesquisa

O primeiro trimestre de 2018 com base no Lucro Presumido, representa o valor total a recolher de $\mathrm{R} \$ 19.606,42$, deste valor, $\mathrm{R} \$ 4.242,57$ refere-se ao adicional de IRPJ, onde este deverá ser apurado somente quando o valor de $\mathrm{R} \$ 20.000,00$ ao mês for ultrapassado, neste caso do Lucro Presumido que é apurado de forma trimestral, ultrapassar o valor de R\$60.000,00. Já na apuração do CSLL, o valor calculado no $1^{\circ}$ trimestre de 2017 , o montante apurado calculou um total de $\mathrm{R} \$ 13.244,40$.

É possível verificar que a empresa objeto de estudo alcançou receitas financeiras no primeiro trimestre de 2018, e seguindo as conformidades da legislação, as mesmas não sofrem aplicação de alíquotas de presunção, devendo somente somar de forma direta na base de cálculo. O montante calculado sob receitas financeiras no $1^{\circ}$ trimestre de 2018 resultou no valor de $\mathrm{R} \$ 12.957,15$, sendo somado de integralmente as alíquotas de $8 \%$ de IRPJ e $12 \%$ de CSLL sob as receitas de mercadorias.

Tabela 7 - Apuração do IRPJ e CSLL - Lucro Presumido - $2^{\circ}$ Trimestre

\begin{tabular}{l|l|l}
\hline ESPECIFICAÇÃO IRPJ CSLL & IRPJ & CSLL \\
\hline Receita Operacional Bruta - Venda de Mercadorias & R\$1.236.076,14 & R\$1.236.076,14 \\
\hline Percentual do Lucro Fixado Fiscalmente (Presunção Lucro) & $8 \%$ & $12 \%$ \\
\hline
\end{tabular}




\begin{tabular}{l|l|l}
\hline Lucro Presumido Venda de Mercadorias & $\mathrm{R} \$ 98.886,09$ & $\mathrm{R} \$ 148.329,14$ \\
\hline Receita Financeira Tributada Integralmente & $\mathrm{R} \$ 15.874,98$ & $\mathrm{R} \$ 15.874,98$ \\
\hline Lucro Presumido Total & $\mathrm{R} \$ 114.761,07$ & $\mathrm{R} \$ 164.204,12$ \\
\hline Alíquotas de IRPJ e CSLL & $15 \%$ & $9 \%$ \\
\hline Valor de IRPJ e CSLL - Antes do Adicional & $\mathrm{R} \$ 17.214,16$ & $\mathrm{R} \$ 14.778,37$ \\
\hline Adicional de IRPJ - 10\% Sobre o que ultrapassar 60 mil & $\mathrm{R} \$ 5.476,11$ & $\mathrm{R} \$$ \\
\hline Valor a pagar de IRPJ e CSLL & $\mathrm{R} \$ 22.690,27$ & $\mathrm{R} \$ 14.778,37$ \\
\hline
\end{tabular}

Fonte: Dados da pesquisa

Após a análise dos cálculos de IRPJ e CSLL do segundo trimestre de 2018, conforme a Tabela 7, com base no regime tributário do Lucro Presumido, se obtém um montante de $\mathrm{R} \$ 22.690,27$ para e de $\mathrm{R} \$ 14.778,37$ para IRPJ e CSLL respectivamente. O valor de IRPJ incidiu o adicional de $10 \%$ sobre o valor que ultrapasse os $\mathrm{R} \$ 60.000,00$ no trimestre, sendo assim 0 cálculo corresponde a $\mathrm{R} \$ 5.476,11$.

Tabela 8 - Apuração do IRPJ e CSLL - Lucro Presumido - $3^{\circ}$ Trimestre

\begin{tabular}{l|l|l}
\hline ESPECIFICAÇÃO IRPJ CSLL & IRPJ & CSLL \\
\hline Receita Operacional Bruta - Venda de Mercadorias & $\mathrm{R} \$ 1.158 .336,10$ & $\mathrm{R} \$ 1.158 .336,10$ \\
\hline Percentual do Lucro Fixado Fiscalmente (Presunção Lucro) & $8 \%$ & $12 \%$ \\
\hline Lucro Presumido Venda de Mercadorias & $\mathrm{R} \$ 92.666,89$ & $\mathrm{R} \$ 139.000,33$ \\
\hline Receita Financeira Tributada Integralmente & $\mathrm{R} \$ 19.830,12$ & $\mathrm{R} \$ 19.830,12$ \\
\hline Lucro Presumido Total & $\mathrm{R} \$ 112.497,01$ & $\mathrm{R} \$ 158.830,45$ \\
\hline Alíquotas de IRPJ e CSLL & $15 \%$ & $9 \%$ \\
\hline Valor de IRPJ e CSLL - Antes do Adicional & $\mathrm{R} \$ 16.874,55$ & $\mathrm{R} \$ 14.294,74$ \\
\hline Adicional de IRPJ - 10\% Sobre o que ultrapassar 60 mil & $\mathrm{R} \$ 5.249,70$ & $\mathrm{R} \$$ \\
\hline Valor a pagar de IRPJ e CSLL & $\mathrm{R} \$ 22.124,25$ & $\mathrm{R} \$ 14.294,74$ \\
\hline Fonte: Dados da Pesquisa
\end{tabular}

Fonte: Dados da pesquisa

Quando calculadas as contribuições referentes ao terceiro trimestre de 2018, o valor calculado referente do IRPJ a recolher é de $\mathrm{R} \$ 22.124,25$, onde deste resultado, o valor adicional de $10 \%$ é de $\mathrm{R} \$ 5.249,70$, sendo estes exibidos na Tabela 8.

Conforme Tabela 8 acima, observa-se que houve um valor de $\mathrm{R} \$ 19.830,12$, referente a receita financeira, onde a mesma será adicionada aos valores de presunção de venda de mercadorias.

Já na CSLL, o valor calculado referente ao terceiro trimestre de 2018 foi no montante de $R \$ 14.294,74$, dando seguimento as apurações, também foi verificado que os valores calculados até o $3^{\circ}$ trimestre de 2018, teve um crescimento constante, isso deve-se a circunstância de que no Lucro Presumido, o cálculo do imposto é efetuado em cima do faturamento basicamente falando, e considerando o faturamento crescente da empresa, em 2018 os impostos foram cada vez maiores a cada apuração trimestral.

Na Tabela 9, demonstra-se os valores referentes ao último trimestre do ano civil de 2018. Como nos demais cálculos apresentados até o presente momento, utilizando o valor da 
receita operacional bruta com a venda de mercadorias multiplicada pelas alíquotas de presunção, somada as receitas financeiras no qual soma-se sua totalidade ao Lucro Presumido total. Ressalta-se que a empresa possui valores oriundos de receita financeira que devem ser somados a base de cálculo, após as presunções.

Tabela 9 - Apuração do IRPJ e CSLL - Lucro Presumido - $4^{\circ}$ Trimestre

\begin{tabular}{l|l|l}
\hline ESPECIFICAÇÃO IRPJ CSLL & IRPJ & CSLL \\
\hline Receita Operacional Bruta - Venda de Mercadorias & $\mathrm{R} \$ 1.493 .069,13$ & $\mathrm{R} \$ 1.493 .069,13$ \\
\hline Percentual do Lucro Fixado Fiscalmente (Presunção Lucro) & $8 \%$ & $12 \%$ \\
\hline Lucro Presumido Venda de Mercadorias & $\mathrm{R} \$ 119.445,53$ & $\mathrm{R} \$ 179.168,30$ \\
\hline Receita Financeira Tributada Integralmente & $\mathrm{R} \$ 24.912,48$ & $\mathrm{R} \$ 24.912,48$ \\
\hline Lucro Presumido Total & $\mathrm{R} \$ 144.358,01$ & $\mathrm{R} \$ 204.080,78$ \\
\hline Alíquotas de IRPJ e CSLL & $15 \%$ & $9 \%$ \\
\hline Valor de IRPJ e CSLL - Antes do Adicional & $\mathrm{R} \$ 21.653,70$ & $\mathrm{R} \$ 18.367,27$ \\
\hline Adicional de IRPJ - 10\% Sobre o que ultrapassar 60 mil & $\mathrm{R} \$ 8.435,80$ & $\mathrm{R} \$$ \\
\hline Valor a pagar de IRPJ e CSLL & $\mathrm{R} \$ 30.089,50$ & $\mathrm{R} \$ 18.367,27$ \\
\hline Fonte: Dados da Pesquisa
\end{tabular}

Fonte: Dados da pesquisa

Após efetuar o cálculo do $4^{\circ}$ e último semestre de 2018, foi possível identificar que neste trimestre os tributos de IRPJ e CSLL foram os mais elevados, comparado aos outros três trimestres, chegando ao valor de $\mathrm{R} \$ 30.089,50$ e $\mathrm{R} \$ 18.367,27$ para IRPJ e CSLL nesta ordem, onde, no valor do IRPJ houve adicional de $10 \%$ que totalizou um valor de $\mathrm{R} \$ 8.435,80$ pois ultrapassou o valor de $\mathrm{R} \$ 60.000,00$ de lucro presumido no trimestre.

A Tabela 10 tem por objetivo evidenciar todos os tributos em ambos os regimes tributários, para efeito de comparação e interpretação:

Tabela 10 - Comparativo Anual: Lucro Real versus Lucro Presumido

\begin{tabular}{l|l|l|l}
\hline Tributo & Lucro Real & Lucro Presumido & Diferença \\
\hline PIS & $R \$ 13.189,00$ & $R \$ 17.632,26$ & $-R \$ 4.443,26$ \\
\hline COFINS & $R \$ 60.749,33$ & $R \$ 81.379,68$ & $-R \$ 20.630,35$ \\
\hline IRPJ & $R \$ 77.818,92$ & $R \$ 94.510,44$ & $-R \$ 16.691,52$ \\
\hline CSLL & $R \$ 36.654,81$ & $R \$ 60.684,78$ & $-R \$ 24.029,97$ \\
\hline ICMS & $R \$ 95.920,00$ & $R \$ 95.920,00$ & $R \$ 0,00$ \\
\hline IPI & $R \$ 39.966,67$ & $R \$ 39.966,67$ & $R \$ 0,00$ \\
\hline CPP & $R \$ 187.132,41$ & $R \$ 187.132,41$ & $R \$ 0,00$ \\
\hline TOTAL & $R \$ 511.431,14$ & $R \$ 577.226,24$ & $-R \$ 65.795,10$
\end{tabular}

Fonte: Dados da pesquisa

Na Tabela 10 é possível observar que existe uma diferença significativa entre os métodos de recolhimento. Quando o atual regime tributário (Lucro Real) com o possível regime de recolhimento (Lucro Presumido), observa-se uma economia de mais de 65 mil reais. Ou seja, o atual regime de enquadramento tributário é o mais vantajoso para a empresa.

Destaca-se ainda, que os tributos de ICMS, IPI e CPP não possuem diferenças de 
recolhimento entre estes dois regimes tributários, conforme menciona o Oliveira et al. (2013).

\section{CONSIDERAÇÕES FINAIS}

O Planejamento tributário deve ser sempre elaborado conforme rege a legislação, sendo assim, conhecer os decretos, leis e normativos é de extrema importância para a execução desta atividade. Deve ser considerado como ferramenta de estratégia para as empresas, pois a empresa conseguindo reduzir seus gastos com tributos, torna-se mais competitiva no mercado, pois na crise econômica na qual nos deparamos, é essencial a diminuição destes custos, pois sabe-se que que estes custos afetam o faturamento de uma empresa.

Foram apurados os valores dos tributos de PIS, COFINS, IRPJ, CSLL, ICMS, IPI e CPP, com o propósito de compará-los nos regimes tributários Lucro Real e Lucro Presumido, conforme citado anteriormente, os valores dos tributos de ICMS, IPI e CPP nestes regimes de tributação, porém, foram calculados para que fosse exposto a carga tributária total da empresa no ano de 2018.

Após efetuados todos os cálculos e apurações devidas, percebeu-se que o regime menos oneroso para a empresa objeto de estudo continua sendo o Lucro Real, no qual é o regime que a empresa utiliza, isto significa que, além da constante mudança na legislação, presume-se que a prática do planejamento tributário deve ser efetuada de modo periódico, com a finalidade de que o regime escolhido, sempre será o mais vantajoso.

Pode-se destacar que a forma de apuração pelo regime tributário Lucro Real é a mais exaustiva para o contabilista, porém se verificado a comparação dos regimes, apresenta-se muito mais vantajosa e menos onerosa em relação ao Lucro Presumido. Ademais, vale destacar que a situação atual da empresa pode ser alterada com o passar dos anos, tendo em vista alterações em nossa legislação, desta forma, é de responsabilidade da empresa, examinar e analisar de período em período, de preferência de ano em ano, um novo planejamento tributário, para que de forma preventiva, seja possível visualizar e evidenciar uma apropriada e adequada elisão fiscal.

\section{REFERÊNCIAS}

ALVES, Adler A. C. A legalidade da fusão, cisão e incorporação de empresas como instrumentos de planejamento tributário. Disponível em: <https://jus.com.br/artigos/3583/alegalidade-da-fusao-cisao-e-incorporacao-de-empresas-como-instrumentos-deplanejamento-tributario/2>. 2006, p. 02. Acesso em: 03 de Março de 2019.

BRASIL. 1966. Código Tributario Nacional. Disponível em: 
<http://www.planalto.gov.br/ccivil_03/Leis/L5172.htm>. Acesso em 10 de Maio de 2019.

BRASIL. 1988. Constituição Federal. Disponível em:

$<$ http://www.planalto.gov.br/ccivil_03/constituicao/constituicaocompilado.htm>. Acesso em 28 de Março de 2019.

BRASIL. 1990. LEI № 8.034, de 12 de Abril de 1990. Disponível em:

<http://www.planalto.gov.br/ccivil_03/leis/L8034.htm>. Acesso em 06 de Junho de 2019.

BRASIL. 1990. LEI № 8.036, de 11 de Maio de 1990. Disponível em:

<http://www.planalto.gov.br/ccivil_03/Leis/L8036consol.htm>. Acesso em 06 de Junho de 2019.

BRASIL. 1995. LEI N 8.981, de 20 de Janeiro de 2018. Disponível em:

<http://www.planalto.gov.br/ccivil_03/leis/L8981.htm>. Acesso em 31 de Maio de 2019.

BRASIL. 2013. LEI N 12.814, de 16 de Maio de 2013. Disponível em:

<http://www.planalto.gov.br/ccivil_03/_ato2011-2014/2013/lei//12814.htm>. Acesso em 27 de Maio de 2018.

CASSONE, Vittorio. Direito Tributário. 21. Ed. São Paulo: Atlas, 2010.

CHAVES, Francisco Coutinho. Planejamento tributário na prática: gestão tributária aplicada. 2. ed. - São Paulo: Atlas, 2010.

CREPALDI, Silvio Aparecido. Planejamento Tributário. 8a Ed. São Paulo: Atlas, 2012.

FABRETTI, Láudio Camargo. Contabilidade Tributária. 2. Ed. São Paulo: Atlas, 2009.

FABRETTI, Láudio Camargo. Contabilidade Tributária. 13a Ed. São Paulo: Atlas, 2013.

HIGUCHI, Hiromi. Imposto De Renda Das Empresas: Interpretação E Prática. 40.ed. São Paulo: IR Publicações, 2015.

LATORRACA, Nilton. Direito tributário: impostos de renda das empresas. 15. Ed. São Paulo, Atlas, 2000.

MALKOWSKI, Almir. Planejamento Tributário e a Questão da Elisão Fiscal. 1a Ed. Leme: LED Editora de Direito, 2000.

MARION, José Carlos. Contabilidade Empresarial. 10. ed. São Paulo: Atlas, 2003.

MUNIZ, Humberto. Planejamento Tributário como Ferramenta para Redução de Impostos. Artigo. Março, 2012. Disponível em: <

http://www.contabeis.com.br/artigos/708/planejamento-tribuitario-como-ferramenta- 
parareducao-de-impostos/>. Acesso em: 04 de Março de 2019.

OLIVEIRA, Luís Martins de et al. Manual de contabilidade tributária. 2 ed. São Paulo: Atlas, 2003.

OLIVEIRA, Gustavo Pedro de. Contabilidade Tributária. 3. Ed. São Paulo: Saraiva, 2009.

OLIVEIRA, Gustavo Pedro. Contabilidade Tributaria. 3 .Ed. Paulo: Saraiva 2011.

OLIVEIRA, L. M.et al. Manual de Contabilidade Tributária. 11ạ Ed. São Paulo: Atlas, 2012.

OLIVEIRA, Gustavo Pedro de. Contabilidade Tributária. 4ạ Ed. São Paulo: Saraiva, 2013.

PRODANOV, Cleber Cristiano; FREITAS, Ernani Cesar de. Metodologia do Trabalho Científico. Novo Hamburgo: Feevale, 2013.

YOUNG, Lúcia Helena Briski. Planejamento Tributário: Fusão, Cisão e Incorporação. Curitiba: Jaruá, 2009. 